\title{
Twisting about Constrained Line of Parallel Purlins Inter Braced by Sagrods Under Wind Suctions
}

\author{
Kaiqi SUN ${ }^{1}$, Genshu TONG ${ }^{2 *}$, Lei ZHANG $^{3}$ \\ (Institute of High-Performance Materials and Structures, Zhejiang University, Hangzhou 310058, China) \\ 1 Ms Student, skq199101@sina.com \\ 2 Corresponding Author: Professor of Structural Engineering, Tonggs@zju.edu.cn \\ 3 Associate Professor of Structural Engineering, Celzhang@zju.edu.cn
}

\begin{abstract}
Simply supported purlins inter braced by one line of sagrods in a parallel purlin system under wind suction are analyzed. The sagrods are assumed to be zigzag placed with $30 \sim 50 \mathrm{~mm}$ offset in adjacent spacing. The effect of this offset and the local deformation on the effectiveness of sagrod is analyzed. A purlin is divided into 3 segments by offsetted sagrods, and the general solution is found for such a purlin under wind suction. The solution is then extended to a parallel purlin system to determine the deformations of all purlins in the system. Examples are given to reveal the bracing effect of sagrods to purlins away from the sagrod anchor spacing. It is found that the sagrod bracing effect drops quickly as the number of spacings to the sagrod anchor spacing increases. The deformation of the last purlin in the 10 purlin system is close to a purlin without sagrod if the purlin thickness is $1.5 \mathrm{~mm}$. FE analysis is carried out to verify the analytic results and excellent agreement is found. Simplified equations are proposed to find the tensile forces in sagrods, purlin deformations and internal forces easily. Practical meaning of this study may be formulated as follows: (1) the distance of two diagonally braced spacing, as shown in Fig. 1, should be smaller if the purlin thickness is small; (2) it is welcome to take measures to reduce the local deformation of purlin web at the sagrod points.
\end{abstract}

Keywords: purlin; line of parallel purlins; C-section; sagrod; offset

\section{Introduction}

The Chinese technical code of cold-formed thin-wall steel structures (GB 50018-2002) requires that purlins with a span of more than $4 \mathrm{~m}$ shall be braced by sagrods. Sagrods are used to connect parallel purlins and transfer the bracing effect of the first diagonal brace to the remaining purlins, as shown in Fig. 1. Deformations take place in parallel purlins together under wind suction.

In current design practice the sagrods are assumed to be able to provide full bracing to purlins, i.e., in the moment analysis, the purlins are assumed to be a continuous beam with intermediate rigid support at the cross-section of sagrods. But Dimos Polyzois [1] have found that the sagrods are unable to prohibit the lateral movement of the purlin at the sagrod cross-section. The thickness of the purlin web is usually $1.5 \mathrm{~mm}$ to $2.5 \mathrm{~mm}$, and are easy to be locally deformed under the action of sagrod tension [2 -6], see Fig.3.

We noted that the sagrods in the adjacent spaces have offsets, tensile forces in sagrods will produce distortional deformation in purlin webs, leading to remarkable reduction in the effective stiffness of the sagrods. Based on the study of twisting of simply supported purlin with one sagrod under wind suction with roof sheeting connected to the top flange of the purlin by self-drilled screws in Ref [2], the deformations and stresses of parallel purlins in system under wind suction are investigated in this paper.

\section{Twisting about line of parallel purlins inter braced by offsetted sagrods}

The sagrods connected to one purlin are arranged with longitudinal offset (see Fig. 2a), the purlin is divided into 3 segments (see Fig. 2b). This section is focused on the deformation of such a purlin acted by wind suction and the sagrod tensions $T_{1}$ and $T_{2}$, the coordinate system is established as Fig. 2c.

\subsection{General solution to lateral displacement of the shear center of cross-section in single purlin}


Considering the influence of offset in sagrods arrangement (the offset distance of two sagrods is $d$, usually adopted as $30 \mathrm{~mm}$ to $50 \mathrm{~mm}$ ), the model is illustrated in Fig. 2a, $2 \mathrm{~b}$ and $2 \mathrm{c}$. The expression of total potential of the purlin can be given by

$$
\Pi=\frac{1}{2} \int_{0}^{L}\left(E I_{y} u^{\prime \prime 2}+G J \theta^{\prime 2}+E I_{\omega} \theta^{\prime \prime 2}\right) d z+T_{1} u_{b 1}-T_{2} u_{b 2}-\int_{0}^{L} m_{z} \theta d z
$$

in which $L$ is the purlin span; $u$ is the displacement of shear center of cross-section in the $x$ direction and $\theta$ is the twist of cross-section around $z$ axis; $E$ and $G$ are respectively Young's and shear modulus of material; $I_{y}$ and $I_{\omega}$ are respectively the second moment of area about $y$ axis and the warping inertia moment of cross-section; $J$ is the free torsion constant of the cross-section; $T_{1}, T_{2}$ are the tensile forces in sagrods connected to the purlin respectively; $u_{b 1}, u_{b 2}$ are respectively the lateral displacements of the purlin web at the sagrod points in the $x$ direction. The distributed torque around $z$ axis in top flange is

$$
m_{z}=q_{y} e_{y}
$$

Since the top flange of the $\mathrm{C}$-section purlin is horizontally restrained, the relation between the displacement $u$ and the twist $\theta$ can be expressed as

$$
u=0.5 h \theta, u_{b 1}=e_{0} \theta_{L 1}, u_{b 2}=e_{0} \theta_{L 2}
$$

in which $\theta_{L 1}, \theta_{L 2}$ are respectively the rotations at the sagrod cross-sections.

Substituting Eqs. (3a)-(3c) into Eq. (1) leads to

$$
\Pi=\frac{1}{2} \int_{0}^{L}\left(E I_{\omega}^{\prime} \theta^{\prime \prime 2}+G J \theta^{\prime 2}\right) d z+T_{1} e_{0} \theta_{L 1}-T_{2} e_{0} \theta_{L 2}-\int_{0}^{L} m_{z} \theta d z
$$

where

$$
E I_{\omega}^{\prime}=0.25 h^{2} E I_{y}+E I_{\omega}
$$

The variation of the total potential Eq. (4), after partial integration, is

$$
\delta \Pi=\left.E I_{\omega}^{\prime} \theta^{\prime \prime} \delta \theta^{\prime}\right|_{0} ^{L}+\left.\left(G J \theta^{\prime}-E I_{\omega}^{\prime} \theta^{\prime \prime \prime}\right) \delta\right|_{0} ^{L}-\int_{0}^{L}\left(G J \theta^{\prime \prime}-E I_{\omega}^{\prime} \theta^{(4)}+m_{z}\right) \delta \theta d z+T_{1} e_{0} \delta \theta_{L 1}-T_{2} e_{0} \delta \theta_{L 2}=0
$$

The following equilibrium equation can be obtained:

$$
\theta^{(4)}-\lambda^{2} \theta^{\prime \prime}=\frac{m_{z}}{E I_{\omega}^{\prime}}
$$

where

$$
\lambda=\sqrt{\frac{G J}{E I_{\omega}^{\prime}}}
$$

Considering the boundary and continuity conditions:

(1) In simply restrained sections, as well as where $z=0$ and $z=L$ :

$$
\theta=0, \quad \theta^{\prime \prime}=0
$$

(2) In the sagrod cross-sections, as well as where $z=L_{1}$ and $z=L_{2}$ :

$$
\begin{aligned}
& \theta_{L 1-}=\theta_{L 1+}, \quad \theta_{L 2-}=\theta_{L 2+} \\
& \theta_{L 1-}^{\prime}=\theta_{L 1+}^{\prime}, \quad \theta_{L 2-}^{\prime}=\theta_{L 2+}^{\prime} \\
& \theta_{L 1-}^{\prime \prime}=\theta_{L 1+}^{\prime \prime}, \quad \theta_{L 2-}^{\prime \prime}=\theta_{L 2+}^{\prime \prime} \\
& \left(G J \theta^{\prime}-E I_{\omega}^{\prime} \theta^{\prime \prime \prime}\right)_{L 1-}-\left(G J \theta^{\prime}-E I_{\omega}^{\prime} \theta^{\prime \prime \prime}\right)_{L 1+}+T_{1} e_{0}=0 \\
& \left(G J \theta^{\prime}-E I_{\omega}^{\prime} \theta^{\prime \prime \prime}\right)_{L 2-}-\left(G J \theta^{\prime}-E I_{\omega}^{\prime} \theta^{\prime \prime \prime}\right)_{L 2+}-T_{2} e_{0}=0
\end{aligned}
$$

in which the subscripts $L 1-$ and $L 2$ - represent the left sides (where the $z$ coordinate is smaller) of the sagrod cross-sections (where $z=L_{1}$ and $z=L_{2}$ ), and the subscripts $L 1+$ and $L 2+$ represent the right side of the sagrod 
cross-sections. Considering Eqs. (7), (9c) and (9d), Eq. (9g) and (9h) can be simplified as

$$
\theta_{L 1-}^{\prime \prime \prime}-\theta_{L 1+}^{\prime \prime \prime}=\frac{T_{1} e_{0}}{E I_{\omega}^{\prime}}, \quad \theta_{L 2-}^{\prime \prime \prime}-\theta_{L 2+}^{\prime \prime \prime}=-\frac{T_{2} e_{0}}{E I_{\omega}^{\prime}}
$$

The solutions of Eq. (6) are:

(1) $0 \leq z \leq L_{1}: \theta_{L 1-}=C_{1}+C_{2} z+C_{3} \sinh \lambda z+C_{4} \cosh \lambda z-\frac{m_{z}}{2 G J} z^{2}$

(2) $L_{1} \leq z \leq L_{2}: \theta_{L 1+}=C_{5}+C_{6} z+C_{7} \sinh \lambda z+C_{8} \cosh \lambda z-\frac{m_{z}}{2 G J} z^{2}$

(3) $L_{2} \leq z \leq L: \theta_{L 2+}=C_{9}+C_{10} z+C_{11} \sinh \lambda z+C_{12} \cosh \lambda z-\frac{m_{z}}{2 G J} z^{2}$

Substituting the boundary and continuity conditions (Eqs. (8)-(10)) into Eqs. (11a)-(11c), the constants $C_{1}-C_{12}$ can be determined as

$$
\begin{aligned}
& C_{1}=-\frac{m_{z}}{G J \lambda^{2}} \\
& C_{2}=\frac{m_{z} L}{2 G J}+\frac{T_{2} L_{1}-T_{1} L_{2}}{G J L} e_{0} \\
& C_{3}=-\frac{m_{z}}{G J \lambda^{2}} \tanh \frac{\lambda L}{2}+\frac{T_{1} \sinh \lambda L_{2}-T_{2} \sinh \lambda L_{1}}{G J \lambda \sinh \lambda L} e_{0} \\
& C_{4}=\frac{m_{z}}{G J \lambda^{2}} \\
& C_{5}=-\frac{m_{z}}{G J \lambda^{2}}-\frac{T_{1} L_{1} e_{0}}{G J} \\
& C_{6}=\frac{m_{z} L}{2 G J}+\frac{T_{2} L_{1}+T_{1} L_{1}}{G J L} e_{0} \\
& C_{7}=-\frac{m_{z}}{G J \lambda^{2}} \tanh \frac{\lambda L}{2}-\frac{e_{0} \sinh \lambda L_{1}}{\lambda G J}\left(\frac{T_{1}}{\tanh \lambda L}+\frac{T_{2}}{\sinh \lambda L}\right) \\
& C_{8}=\frac{m_{z}}{\lambda^{2} G J}+\frac{T_{1} e_{0}}{\lambda G J} \sinh \lambda L_{1} \\
& C_{9}=-\frac{m_{z}}{G J \lambda^{2}}+\frac{T_{2} L_{2}-T_{1} L_{1}}{G J} e_{0} \\
& C_{10}=\frac{m_{z} L}{2 G J}+\frac{T_{1} L_{1}-T_{2} L_{2}}{G J L} e_{0} \\
& C_{11}=-\frac{m_{z}}{G J \lambda^{2}} \tanh \frac{\lambda L}{2}+\frac{T_{2} \sinh \lambda L_{2}-T_{1} \sinh \lambda L_{1}}{G J \lambda \tanh \lambda L} e_{0} \\
& C_{12}=\frac{m_{z}}{G J \lambda^{2}}+\frac{T_{1} \sinh \lambda L_{1}-T_{2} \sinh \lambda L_{2}}{G J \lambda} e_{0}
\end{aligned}
$$

The lateral displacements at the connecting points of the sagrods on the purlin web (where $z=L_{1}$ and $z=L_{2}$ ) are expressed by

$$
\begin{aligned}
& u_{b 1}=g_{1} T_{1}+g_{2} T_{2}+g_{3} m_{z} \\
& u_{b 2}=-g_{1} T_{2}-g_{2} T_{1}+g_{3} m_{z}
\end{aligned}
$$

where 


$$
\begin{aligned}
& g_{1}=\frac{e_{0}^{2}}{G J} \frac{L \cosh \lambda L-L \cosh \lambda d-2 \lambda L_{1} L_{2} \sinh \lambda L}{2 \lambda L \sinh \lambda L} \\
& g_{2}=\frac{e_{0}^{2}}{G J} \frac{\lambda L_{1}^{2} \sinh \lambda L-L \sinh ^{2} \lambda L_{1}}{\lambda L \sinh \lambda L} \\
& g_{3}=\frac{e_{0}}{G J} \frac{2 \sinh \lambda L_{1}+2 \sinh \lambda L_{2}+\left(\lambda^{2} L_{1} L_{2}-2\right) \sinh \lambda L}{2 \lambda^{2} \sinh \lambda L}
\end{aligned}
$$

Since the offset distance of two sagrods connected to the same purlin is much less than the purlin span $(d<L L)$, which means $L_{1} \approx L / 2, L_{2} \approx L / 2$, the following relationship can be obtained in approximate solution:

$$
\frac{g_{1}}{f_{3}} \approx 1, \frac{g_{2}}{f_{3}} \approx-1, \frac{g_{3}}{f_{4}} \approx 1
$$

in which $f_{3}$ and $f_{4}$ are determined by substituting $d=0$ into Eqs. (14a)-(14c):

$$
\begin{aligned}
& f_{3}=\frac{e_{0}^{2}}{2 \lambda G J}(\tanh 0.5 \lambda L-0.5 \lambda L) \\
& f_{4}=\frac{e_{0}}{G J \lambda^{2}}\left(\frac{1}{\cosh 0.5 \lambda L}-1+\frac{1}{8} \lambda^{2} L^{2}\right)
\end{aligned}
$$

The lateral displacement and the twist of the section if the sagrods were connected to purlin web without offset (i.e. $d=0$ ) can be expressed by

$$
\begin{aligned}
& u_{L}=f_{3} F+f_{4} m_{z} \\
& \theta_{L}=f_{1} F+f_{2} m_{z}
\end{aligned}
$$

where

$$
F=T_{1}-T_{2}, \quad f_{1}=f_{3} / e_{0}, \quad f_{2}=f_{4} / e_{0}
$$

The twisting of the purlin along span can be approximated by

$$
\theta=\frac{e_{0}}{2 G J}\left(\frac{\sinh \lambda z}{\lambda \cosh \lambda l}-z\right) F+\frac{1}{G J \lambda^{2}}\left(-1+\lambda^{2} l z-\frac{\sinh \lambda l \sinh \lambda z}{\cosh \lambda l}+\cosh \lambda z-\frac{\lambda^{2} z^{2}}{2}\right) m_{z}
$$

\subsection{Effective stiffness of sagrods}

\subsubsection{Tensile stiffness of sagrods}

Supposing that the sectional area and the length of sagrods are respectively $A_{b}$ and $l_{b}$, the axial stiffness of the sagrods is

$$
k_{b}=\frac{E A_{b}}{l_{b}}=\frac{1}{f_{b}}
$$

where $f_{b}$ is the flexibility corresponding to the axial stiffness.

The tensile force in the sagrod produce local bending deformation of the purlin web, as shown in Fig. 3. The stiffness corresponding to this local deformation is approximated by

$$
k_{w}=\frac{13 E t^{3}}{h^{2}(1-\cos 2 \pi \xi)^{0.65\left(\xi^{2}-\xi+1.25\right)}}\left(1-25 \frac{t^{1.5}}{h^{1.5}}\right)=\frac{1}{f_{w}}
$$

where $f_{w}$ is the flexibility corresponding to $k_{w} ; h$ is the distance between the top and bottom flanges of the cross-section; $t$ is the thickness of the purlin section; $\xi$ is the normalized distance between the sagrod location and the bottom flange given by

$$
\xi=1-\frac{e_{0}}{h}
$$


where $e_{0}$ is the distance between the middle thickness of the top flange of cross-section and the sagrod location (shown in Fig. 1c).

The local deformation of purlin web result in a considerable reduction in effectiveness of lateral restraint to purlin by sagrod. Two kinds of deformations (sagrod elongation and web local deformation) occur and must be considered simultaneously, the effective stiffness of the sagrod is thus reduced to

$$
k_{\mathrm{LT}}=\frac{k_{\mathrm{w}} k_{\mathrm{b}}}{k_{\mathrm{b}}+k_{\mathrm{w}}}
$$

Because $k_{w}$ is far less than $k_{b}, k_{\mathrm{LT}}$ is less than but close to $k_{w}$, and $k_{\mathrm{LT}}$ is $(1 \% \sim 17 \%) k_{b}$, dependent on the thickness and the sagrod location on the web.

Utilizing Eq. (17b), the twist of the sagrod cross-section with sagrod connected in the case of single purlin with one sagrod can be obtained by

$$
\theta_{L}=\frac{f_{2}}{1-f_{1} k_{L T} e_{0}} m_{z}
$$

And the tensile force in the sagrod is

$$
F_{\mathrm{LT}}=k_{\mathrm{LT}} e_{0} \theta_{L}=\frac{f_{4}}{f_{\mathrm{w}}+f_{\mathrm{b}}-f_{3}} m_{z}
$$

\subsubsection{The local flexural stiffness of purlins}

Fig. 4 shows a kind of deformation occurring as a result of the forces in offsetted sagrods. The two tensile forces in the offsetted sagrods constitute a local bending moment. The aim of this section is to determine the local flexural stiffness of resisting this local bending moment by observing the local deformation caused by this moment in FE analysis.

The purlins are modeled using the elastic thin shell element SHELL63 of ANSYS in FE analysis. The lengths of all purlins are $5 \mathrm{~m}$, which are longitudinally divided into 1000 meshes. Two unit concentrated forces are applied oppositely perpendicular to the purlin web with a distance of $d$; the positions of the sagrod cross-sections are symmetric about the midspan of the purlin; the sagrod positions on the cross-section are $e_{0}=0.5 \mathrm{~h}$. The horizontal and vertical displacements (in $x$ and $y$ directions, see Fig. 2c) of the middle width of the top flange are restrained at intervals of $250 \mathrm{~mm}$ in the longitudinal direction, to simulate the lateral braces from the roof sheeting. To prohibit the twisting of the cross section, the $x$-displacement of the bottom web-to-flange juncture is also restrained. The model in FE analysis is shown in Fig. 4.

In Fig. 4a, denote the displacements at the loaded points by $\delta_{M}$. In Fig. 3b, there is only one sagrod, we exert also a unit force at the sagrod point, and denote the displacement at the loaded point by $\delta_{0} . \delta_{M}$ is related to $\delta_{0}$ by the following equation

$$
\delta_{0}=2 \chi \delta_{M}
$$

Where $\chi$ is a parameter to be determined by FE analysis. $\delta_{0}$ is the reciprocal of $k_{w}$ :

$$
k_{w}=\frac{1}{\delta_{0}}
$$

And the local bending stiffness $k_{\theta}$ of resisting the deformation in Fig. 4 is

$$
k_{\theta}=\frac{M}{\theta}=\frac{1 \times d}{2 \delta_{M} / d}=\frac{d^{2}}{2 \delta_{M}}=\frac{2 \chi d^{2}}{2 \delta_{0}}=\chi d^{2} k_{w}
$$

in which $M$ is the local bending moment by the two opposite unit concentrated loads; $\theta$ is the angle between the line connecting two loaded points with displacements and the longitudinal axis; $\chi$ is a coefficient for 
approximation.

In FE analysis, 30 typical cold-formed steel sections are adopted where the thickness and height of cross sections are $1.5 \sim 3.5 \mathrm{~mm}$ and $140 \sim 250 \mathrm{~mm}$, respectively. The offset distance $d$ is $30 \sim 50 \mathrm{~mm}$ at intervals of $5 \mathrm{~mm}$. Utilizing the FE results of displacement $\delta_{M}$, considering the approximate solution of $k_{w}$ in Eq. (21), an almost accurate approximation of coefficient $\chi$ can be obtained as

$$
\chi_{\xi=0.5}=0.158 \rho^{-1.6}+0.4
$$

where $\rho=d / h$. By varying the distance $e_{0}(\xi=0.375,0.25$ and 0.125$)$, the following equations for $\chi$ are obtained:

$$
\begin{aligned}
& \xi=0.375: \quad \chi=0.147 \rho^{-1.6}+0.43 \\
& \xi=0.25: \quad \chi=0.114 \rho^{-1.6}+0.519 \\
& \xi=0.125: \quad \chi=0.06 \rho^{-1.6}+0.642
\end{aligned}
$$

Based on Eqs. (28a)-(28d), the local bending stiffness can be proposed as

$$
k_{\theta}=k_{w} h^{2}\left[\left(1.86 \xi^{2}-1.86 \xi+0.84\right) \rho^{2}-\left(0.7 \xi^{2}-0.7 \xi+0.017\right) \rho^{0.4}\right]
$$

The flexibility corresponding to this local bending flexural stiffness is

$$
f_{\theta}=\delta_{M=d}=\frac{d^{2}}{2 k_{\theta}}=\frac{0.5 f_{\mathrm{w}}}{1.86 \xi^{2}-1.86 \xi+0.84-\left(0.7 \xi^{2}-0.7 \xi+0.017\right) \rho^{-1.6}}
$$

Comparisons of Eq. (29a) and the FE results with various values of $\xi$ are shown in Fig. 5. It can be observed that Eq. (29a) has excellent accuracy.

\subsection{Twisting about line of parallel purlins}

\subsubsection{Theoretical solution}

In the parallel purlins shown in Fig. $6, u_{i L 1}$ and $u_{i L 2}$ are the $x$-displacements at the sagrod locations in purlin webs (i.e. $z=L_{1}$ and $z=L_{2}$ ) respectively, with local bending deformations included (the subscript $L$ means local bending included); $u_{i 1}$ and $u_{i 2}$ are respectively the $x$-displacements at the same locations with rigid profile assumption; $\theta_{i 1}$ and $\theta_{i 2}$ are respectively the twists of the sections connected with sagrods. The relation between displacements and twists are

$$
u_{i 1}=e_{0} \theta_{i 1}, u_{i 2}=e_{0} \theta_{i 2}
$$

It should be noticed that $u_{i L 1} \neq u_{i 1}, u_{i L 2} \neq u_{i 2}$. The tensile forces in sagrods are computed based on the locations after local deformation. The local web bending deformation is $u_{i 1}-u_{i L 1}, u_{i 2}-u_{i L 2}$ (see Fig. 3c).

The relationship of tensile forces in sagrods, tensile stiffness of sagrods and axial deformation can be obtained by following analysis.

(1) In the first purlin of the parallel purlin system:

In the first purlin (the purlin connected with the sagrod whose other end is completely restrained), considering the tensile stiffness of sagrod itself, the following expressions can be obtained:

$$
\begin{aligned}
& T_{1}=k_{b} u_{1 L 1} \\
& T_{2}=k_{b}\left(u_{2 L 2}-u_{1 L 2}\right)
\end{aligned}
$$

In the first purlin, the local deformation $u_{11}-u_{1 L 1}$ at $z=L_{1}$ is equivalently caused by a tensile force equal to $T_{1}-T_{2}$ applied at the location and a bending moment equal to $d \times T_{2}$ applied around the location, as shown in Fig. 7b. The local flexibilities corresponding to the two types of forces in Fig. $7 \mathrm{~b}$ are $f_{w}$ and $f_{\theta}$ respectively, so one has

$$
f_{w}\left(T_{1}-T_{2}\right)+f_{\theta} T_{2}=u_{11}-u_{1 L 1}
$$


Similarly, referring to Fig. 7(c), one has

$$
f_{\mathrm{w}}\left(T_{1}-T_{2}\right)-f_{\theta} T_{1}=u_{12}-u_{1 L 2}
$$

Considering Eqs. (13a) and (13b), we have

$$
\begin{aligned}
& u_{11}=g_{1} T_{1}+g_{2} T_{2}+g_{3} m_{z} \\
& u_{12}=-g_{2} T_{1}-g_{1} T_{2}+g_{3} m_{z}
\end{aligned}
$$

(2) In the purlin with even number of $i$ :

Following the similar procedure, considering Eqs. (13a) and (13b), we can write out

$$
\begin{aligned}
& T_{i}=k_{b}\left(u_{i L 2}-u_{i-1 L 2}\right) \\
& f_{\mathrm{w}}\left(T_{i}-T_{i+1}\right)-f_{\theta} T_{i}=u_{i 1}-u_{i L 1} \\
& f_{\mathrm{w}}\left(T_{i}-T_{i+1}\right)+f_{\theta} T_{i+1}=u_{i 2}-u_{i L 2} \\
& u_{i 1}=g_{1}\left(-T_{i+1}\right)+g_{2}\left(-T_{i}\right)+g_{3} m_{z} \\
& u_{i 2}=g_{2} T_{i+1}+g_{1} T_{i}+g_{3} m_{z}
\end{aligned}
$$

In the purlin with odd number of $i$ :

$$
\begin{aligned}
& T_{i}=k_{b}\left(u_{i L 1}-u_{i-1 L 1}\right) \\
& f_{\mathrm{w}}\left(T_{i}-T_{i+1}\right)+f_{\theta} T_{i+1}=u_{i 1}-u_{i L 1} \\
& f_{\mathrm{w}}\left(T_{i}-T_{i+1}\right)-f_{\theta} T_{i}=u_{i 2}-u_{i L 2} \\
& u_{i 1}=g_{1} T_{i}+g_{2} T_{i+1}+g_{3} m_{z} \\
& u_{i 2}=-g_{2} T_{i}-g_{1} T_{i+1}+g_{3} m_{z}
\end{aligned}
$$

(3) In the purlin with even $n$ :

$$
\begin{aligned}
& T_{n}=k_{b}\left(u_{n L 2}-u_{n-1 L 2}\right) \\
& f_{\mathrm{w}} T_{n}=u_{n 2}-u_{n L 2} \\
& u_{n 2}=g_{5}\left(-T_{n}\right)+g_{3} m_{z}
\end{aligned}
$$

In the purlin with odd $n$ :

$$
\begin{aligned}
& T_{n}=k_{b}\left(u_{n L 1}-u_{n-1 L 1}\right) \\
& f_{\mathrm{w}} T_{n}=u_{n 1}-u_{n L 1} \\
& u_{n 1}=g_{1} T_{n}+g_{3} m_{z}
\end{aligned}
$$

By eliminating the terms of displacements, a set of simultaneous equations combining Eqs. (31)-(35) (compatible with arbitrary value of $i$ or $n$ ) can be obtained as

$$
\begin{aligned}
& \beta T_{1}-T_{2}=g_{3}^{\prime} m_{z} \\
& -T_{i-1}+\alpha T_{i}-T_{i+1}=0 \\
& -T_{n-1}+\alpha T_{n}=0
\end{aligned}
$$

where (considering $\frac{g_{1}}{f_{3}} \approx 1, \frac{g_{2}}{f_{3}} \approx-1, \frac{g_{3}}{f_{4}} \approx 1$ )

$$
\begin{aligned}
& \alpha=-\frac{2 f_{w}+f_{b}-2 g_{1}}{f_{\theta}-f_{w}-g_{2}} \approx 2+\gamma \\
& \beta=-\frac{f_{\mathrm{w}}+f_{\mathrm{b}}-g_{1}}{f_{\theta}-f_{\mathrm{w}}-g_{2}} \approx 1+\frac{f_{\mathrm{b}}+f_{\theta}}{f_{\mathrm{w}}-\left(f_{\theta}+f_{3}\right)} \\
& g_{3}^{\prime}=-\frac{g_{3}}{f_{\theta}-f_{\mathrm{w}}-g_{2}} \approx \frac{f_{4}}{f_{\mathrm{w}}-\left(f_{\theta}+f_{3}\right)}
\end{aligned}
$$




$$
\gamma=\frac{f_{\mathrm{b}}+2 f_{\theta}}{f_{\mathrm{w}}-\left(f_{\theta}+f_{3}\right)}
$$

Equations (36a, $\mathrm{b}$ and $\mathrm{c})$ are put in matrix form as

$$
\left[\begin{array}{cccccc}
\beta & -1 & 0 & 0 & \cdots & 0 \\
-1 & \alpha & -1 & 0 & \cdots & 0 \\
0 & -1 & \alpha & -1 & \cdots & \cdots \\
\vdots & \vdots & \vdots & \vdots & \vdots & \vdots \\
0 & \cdots & 0 & -1 & \alpha & -1 \\
0 & \cdots & 0 & 0 & -1 & \alpha
\end{array}\right]\left(\begin{array}{c}
T_{1} \\
T_{2} \\
T_{3} \\
\vdots \\
T_{n-1} \\
T_{n}
\end{array}\right)=\left(\begin{array}{c}
g_{3}^{\prime} m_{z} \\
0 \\
\vdots \\
0 \\
\vdots \\
0
\end{array}\right)
$$

Compared with the special case of $d=0$ (i.e. $f_{\theta}=0$ ), the presence of offset distance $d$ between adjacent sagrods makes the sagrod flexibility increase to $f_{b}+2 f_{\theta}$, whereas the flexibility of the first sagrod increases to $f_{b}+f_{\theta}$ since it is connected to the purlin web at one end only, and the flexibility coefficient $f_{3}$ increases to $f_{3}+f_{\theta}$.

Due to the sagrod offset, the effective axial stiffness of the offsetted sagrod is changed from $k_{b}=\frac{1}{f_{b}}$ to $k_{b, d}=\frac{1}{f_{\mathrm{b}}+2 f_{\theta}}$. Fig. 9 presents the reduced effective sagrod axial stiffness due to the sagrod offset, which is $\frac{k_{b, d}}{k_{b}}=\frac{f_{b}}{f_{b}+2 f_{\theta}}$.

The most frequently used value of $d$ are $30 \sim 50 \mathrm{~mm}$, thus $\frac{d}{h}=\frac{30}{140} \sim \frac{50}{140}=0.214 \sim 0.357$, and $\frac{d}{h}=\frac{30}{250} \sim \frac{50}{250}=0.12 \sim 0.2$. From Fig. 9 it can be seen that the effective stiffness of the sagrod is reduced to a very small value.

\subsubsection{Analysis of examples}

In the case of only two purlins, as shown in Fig. 10, by solving Eq. (38), we obtain

$$
\begin{aligned}
& T_{1}=\frac{1}{A_{2}} 4 k_{b} k_{w} k_{\theta}^{2}\left(2 k_{b}+k_{w}-2 g_{1} k_{b} k_{w}\right) g_{3} m_{z} \\
& T_{2}=-\frac{2}{A_{2}} k_{b}^{2} k_{\theta} k_{w}\left(k_{w} d^{2}-2 k_{\theta}-2 g_{2} k_{\theta} k_{w}\right) g_{3} m_{z}
\end{aligned}
$$

in which

$$
A_{2}=4 k_{\theta}^{2}\left(k_{b}+k_{w}\right)^{2}+\left(4 k_{\theta}-d^{2} k_{w}+4 g_{2} k_{\theta} k_{w}\right) d^{2} k_{w} k_{b}^{2}+4\left(2 g_{1}^{2}-g_{2}^{2}\right) k_{\theta}^{2} k_{w}^{2} k_{b}^{2}+4\left(1-4 g_{1} k_{b}-2 g_{2} k_{b}-3 g_{1} k_{w}\right) k_{b} k_{w} k_{\theta}^{2}
$$

Substituting Eq. (39) into Eq. (19), considering Eq. (3a), the theoretical lateral displacements along span in each purlin can be obtained. To examine the theoretical results, a typical example with $\mathrm{FE}$ analysis is developed in which the purlin section $\mathrm{C} 250 \times 75 \times 20 \times 2(h=250 \mathrm{~mm}, b=75 \mathrm{~mm}, c=20 \mathrm{~mm}$ and $t=2 \mathrm{~mm})$ is adopted; the sagrods are arranged with offset of $50 \mathrm{~mm}$ (i.e. $d=50 \mathrm{~mm}$ ) and $\xi=0.5$. In shell element modeling, the lengths of purlins are $5 \mathrm{~m}$, which are longitudinally divided into 2000 meshes with simple restraints at ends by restraining the displacements in the $x$ and $y$ directions of all nodes of the two end sections and the $z$-displacement of the middle height node of one end section. The $x$-displacement of each node at the middle width of the top flange is restrained to simulate the lateral braces from the roof sheeting. The wind suction applied is equal to $1 \mathrm{kN} / \mathrm{m}$, and the tensile stiffness of the sagrod assumed to be $1.5 \mathrm{~m}$ in length with a rod section of $10 \mathrm{~mm}$ in diameter can be calculated 
as $k_{b}=10780 \mathrm{~N} / \mathrm{mm}$. The comparison of theoretical solutions and FE results (adopted as average displacements of top and bottom web-to-flange junctures in sections along span to eliminate the influence of local deformation) is shown in Fig. 11.

It can be observed in Fig. 11 that the theoretical results provide high precision, and the displacements of the same section in two purlins show significant difference, which prove that the offset of sagrods has notable influence on the deformation of purlins, reducing the effectiveness of the sagrods.

In the case of 3 purlins, the comparison of two sets of results are given in Fig. 12.

The results of 10-purlin system are presented in Fig. 13 (only purlins with $i=1,3,5,10$ are shown for a clearer observation). For comparison, the displacements of a purlin without sagrod (denoted as $u_{0}$ ) and of a purlin with 1 sagrod in one-purlin system (denoted as $u_{s}$ ) are also presented in Fig. 13.

Further examples are given in Fig. 14 for purlin sections $\mathrm{C} 140 \times 50 \times 20 \times 2.5$ and $\mathrm{C} 250 \times 75 \times 20 \times 1.5$; $d=30,50 \mathrm{~mm}$ and $\xi=0.25,0.5$.

It can be observed in Fig. 13 and Fig. 14 that

(1) The closed theoretical solutions have excellent agreement with the FE numerical results.

(2) The lateral displacement of a purlin is larger if it is farther away from the anchor point of the first sagrod, implying the bracing effect received by purlins weaken as the purlin is farther away from the anchor point.

(3) The lateral displacements of the farthest purlin reach almost the values of the purlin without sagrod if the thickness of the purlin is $1.5(t=1.5)$, and $d=50, \xi=0.5$. That is, in such a combination of parameters, the sagrod has almost no effect on the last purlin if the total number of purlins is greater than 10 .

(4) the lateral deformation of the first purlin in a parallel purlin system is always greater than that of one purlin system.

\subsubsection{The coefficient of tensions in sagrods}

By observing Eqs. (36a)-(36c), similar relationships of sagrods can be obtained as

$$
\begin{aligned}
& T_{n-1}=\alpha T_{n} \\
& T_{n-2}=\alpha T_{n-1}-T_{n}=\left(\alpha^{2}-1\right) T_{n} \\
& T_{n-3}=\alpha T_{n-2}-T_{n-1}=\left(\alpha^{3}-2 \alpha\right) T_{n} \\
& T_{n-4}=\alpha T_{n-3}-T_{n-2}=\left(\alpha^{4}-3 \alpha^{2}+1\right) T_{n} \\
& T_{n-5}=\alpha T_{n-4}-T_{n-3}=\left(\alpha^{5}-4 \alpha^{3}+3 \alpha\right) T_{n} \\
& T_{n-6}=\alpha T_{n-5}-T_{n-4}=\left(\alpha^{6}-5 \alpha^{4}+6 \alpha^{2}-1\right) T_{n} \ldots \ldots . .
\end{aligned}
$$

It can be observed that the ratio $\alpha_{i}=T_{n-i+1} / T_{n}$ is independent of $n$, this is shown in Fig.15. After some induction, the ratio $\alpha_{i}$ can be expressed by

$$
\begin{array}{ll}
\alpha_{i}=\frac{T_{n-i+1}}{T_{n}}=\sum_{k=1}^{(i+1) / 2} \frac{(-1)^{k-1}}{(k-1) !} \prod_{j=k}^{2 k-2}(i-j) \alpha^{i-2 k+1} & (n \text { is odd }) \\
\alpha_{i}=\frac{T_{n-i+1}}{T_{n}}=\sum_{k=1}^{i / 2} \frac{(-1)^{k-1}}{(k-1) !} \prod_{j=k}^{2 k-2}(i-j) \alpha^{i-2 k+1} & (n \text { is even })
\end{array}
$$

By curve fitting, a simple approximate expression can be obtained with deviations less than $1 \%$ :

$$
\alpha_{i}=\frac{T_{n-i+1}}{T_{n}}=\frac{\sinh \left(\gamma^{0.5025} i\right)}{\sinh \gamma^{0.5025}} \quad i=1,2,3, \ldots \ldots, n
$$

where $\gamma=\alpha-2$. 
Comparisons of $\alpha_{i}$ by Eq. (42) and Eq. (41a, b) are shown in Fig. 16, it can be seen that the approximate expression has high precision.

Considering Eq. (36a), the tensile force in the last sagrod (i.e. $T_{n}$ ) can be obtained by

$$
T_{n}=\frac{g_{3} m_{z}}{\left(f_{b}+f_{w}-g_{1}\right) \alpha_{n}+\left(f_{\theta}-f_{w}-g_{2}\right) \alpha_{n-1}} \approx \frac{f_{4} m_{z}}{\left(f_{b}+f_{w}-f_{3}\right) \alpha_{n}+\left(f_{3}+f_{\theta}-f_{w}\right) \alpha_{n-1}}
$$

which can be simply expressed as

$$
\frac{T_{n}}{F_{L T}}=\frac{1}{\alpha_{n}-\alpha_{n-1} / \beta}
$$

in which $F_{\mathrm{LT}}$ represents the tension in the sagrod when only one purlin presents, and is given by Eq. (25). And because $f_{3}$ is less than 0 , but $-f_{3}$ is far larger than $f_{\mathrm{w}}, f_{\theta}$ and $f_{\mathrm{b}}, \beta$ is greater but close to 1.0 , so

$$
\frac{T_{n}}{F_{L T}}=\frac{1}{\cosh \left(\gamma^{0.5025} n\right)}
$$

The tension in the first sagrod is

$$
\frac{T_{1}}{F_{\mathrm{LT}}}=\frac{\alpha_{n}}{\alpha_{n}-\alpha_{n-1} / \beta} \approx \frac{\tanh \left(\gamma^{0.5025} n\right)}{\sinh \gamma^{0.5025}} \approx \frac{1}{\sinh \gamma^{0.5025}} \quad \text { if } n \geq 8
$$

It can be seen from Eq. (42) and Fig. 16 that the increasing of the total amount of purlins $(n)$ result in significant increment of the coefficient of tension in sagrods $\left(\alpha_{n}\right)$. Consequently, the tensile force in the last sagrod decreases rapidly according to Eq. (42), the bracing effect of the sagrod provided to the last purlin decreases significantly.

The tension in each purlin can be calculated utilizing Eqs. (42) and (43). Substituting the difference between two adjacent sagrods which is assumed as $F_{i}$ (i.e. $F_{i}=T_{i}-T_{i+1}$ ) into Eq. (19), the twists and displacements (Eq. (3a)) of sections along span in each purlin can be obtained.

\subsubsection{The out-of-plane bending moments of sections}

The out-of-plane bending moments (about $y$ axis) of sections can be expressed as

$$
M_{y}=-E I_{y} u^{\prime \prime}=-E I_{y} \frac{1}{2} h \theta^{\prime \prime}
$$

After the forces $F_{i}=T_{i}-T_{i+1}$ is obtained, Eq. (19) is used to find the twist of purlins with $F$ replaced by $F_{i}$ and then $M_{y}$ is computed by Eq. (44). For verification of theoretical solutions, 36 typical examples with various sections and arrangement ways of sagrods are adopted in FE analysis (shown in Table. 1).

With 36 different conditions, the theoretical solutions $M_{y}$ and FE analytic results $M_{y \mathrm{ANSYS}}$ at midspan of the purlin with serial number of 1, 5, 10 in a 10 parallel purlins system are shown in Fig. 17.

Fig. 18 shows the distribution of $M_{\mathrm{y}}$ along span, in which only the $1^{\text {st }}, 5^{\text {th }}$ and $10^{\text {th }}$ purlins are shown. The purlin is $\mathrm{C} 140 \times 50 \times 20 \times 2.5, \xi=0.5$ and $d=50 \mathrm{~mm}$.

It can be seen from Fig. 17 and Fig. 18 that the theoretical solutions of out-of-plane bending moments are in good agreement with the results of FE analysis, except in sections near midspan with considerable distortion. Due to reductions of sagrod stiffness, the out-of-plane bending moments in purlins away from the sagrod anchor span are all positive along span, with no negative bending moment occurs in these purlins, and the bending moments are closer to the purlin without sagrod.

\section{Conclusion}

The deformations and stresses of simply supported purlins with one line of sagrods in parallel purlin system 
under wind suction are investigated in this paper, in which the sagrod offset $30 \sim 50 \mathrm{~mm}$ in adjacent purlin spacing is taken into account. It is found that besides the weakening effect of local deformation of the purlin web at the sagrod point on the effective stiffness of the sagrod, the sagrod offset in adjacent purlin spacing weakens further this effective stiffness. A local flexural stiffness of purlin web $\left(k_{\theta}\right)$ due to the sagrod offset is introduced to consider the effect of sagrod offset.

A purlin is divided into 3 segments by offsetted sagrods, the general solution is found for such a purlin under wind suction. The solution is then extended to a parallel purlin system to determine the deformations of all purlins in the system.

Examples are presented to reveal the bracing effect of sagrods to purlins away from the sagrod anchor spacing. It is found that the sagrod bracing effect drops quickly as the number of spacings to the sagrod anchor spacing increases. The deformation of the last purlin in the 10-purlin system is close to a purlin without sagrod if the purlin thickness is $1.5 \mathrm{~mm}$.

FE analysis is carried out to verify the analytic results and excellent agreement is found.

Simplified equations are proposed to find the tension forces in sagrods and purlin deformations and internal forces easily.

Further practical meaning of this study may be formulated as follows: (1) the distance of two diagonally braced spacing, as shown in Fig.1, should be smaller if the purlin thickness is small. (2) it is welcome to take measures to reduce the local deformation of purlin web at the sagrod points.

\section{Acknowlegement}

The study carried out in this paper is financially supported by Chinese National Science Foundation Under Grant No. 51478421.

\section{References}

[1] D. Polyzois. Sagrods as Lateral Supports for Girts and Purlins. J Struct Eng, ASCE, 1987; 113(7): 1521-1531.

[2] Lei Zhang, Tong GS(2015), Stress analysis on cold-formed C-purlins subjected to wind suction load considering the effective stiffness of anti-sag bar, Thin-Walled Structures, 90(5), 107-118

[3] Lei Zhang, Tong GS(2011), Lateral buckling of eccentrically braced RHS columns, THIN WALLED STRUCTURES, 49(11)1452-1459

[4] Lei Zhang, Tong GS(2016) Lateral buckling of simply supported C- and Z-section purlins with top flange horizontally restrained, THIN-WALLED STRUCTURES, 99(2)155-167

[5] Lei Zhang, Tong GS(2016), Lateral buckling of C-section purlins with one anti-sag bar at middle span section, THIN WALLED STRUCTURES, 102(5)246-257

[6] Q. Wu. Research on Strength Calculation of Cold-formed Purlins under Wind Uplift. MS thesis, Zhejiang University, 2015: 37-67 


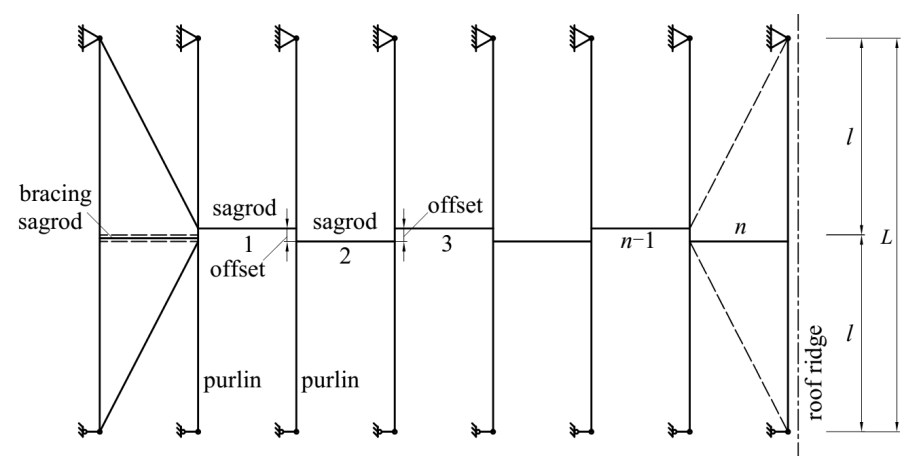

Fig. 1. Arrangement of purlins and sagrods in line of parallel purlins
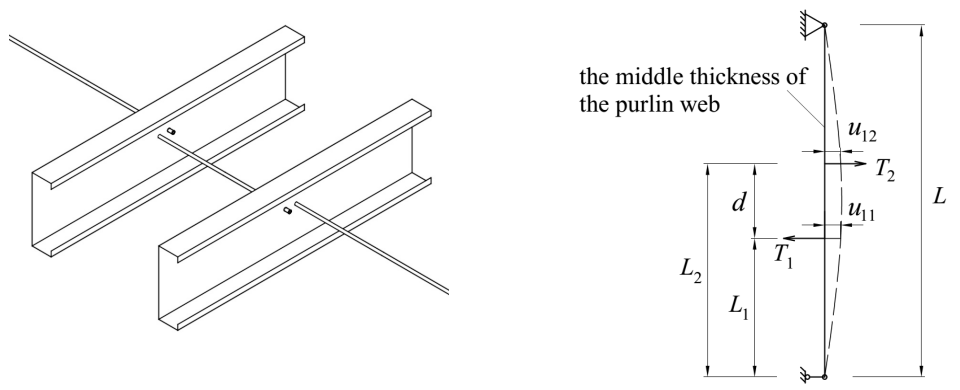

(a) Sagrods with longitudinal offset

(b) Forces applied to the purlin with offset

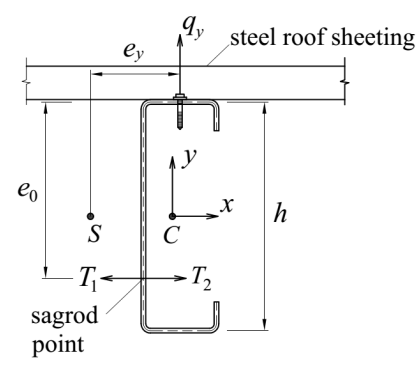

(c) Coordinate system

Fig. 2. Analysis diagram of arbitrary purlin in line of parallel purlins

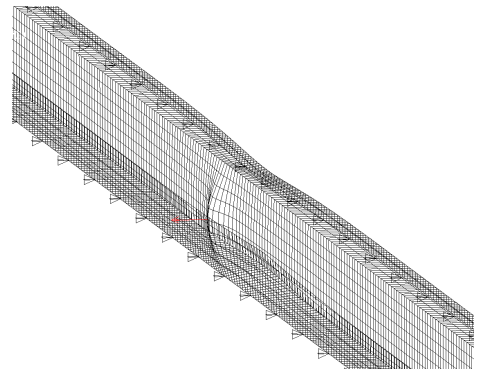

(a) Local deformation of purlin in FE analysis

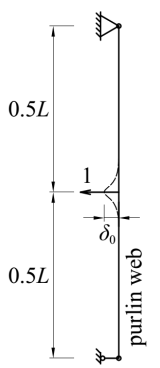

(b) Analysis diagram

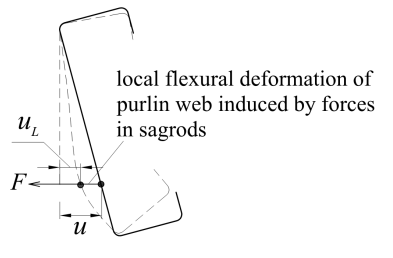

(c) Purlin web with and without local deformation

Fig. 3. Local deformation of purlin web

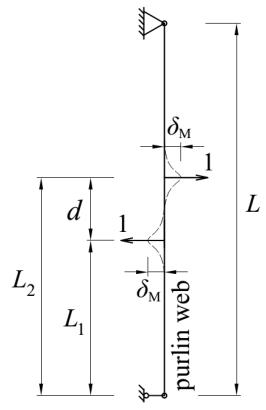

(a) Simple modeling diagram

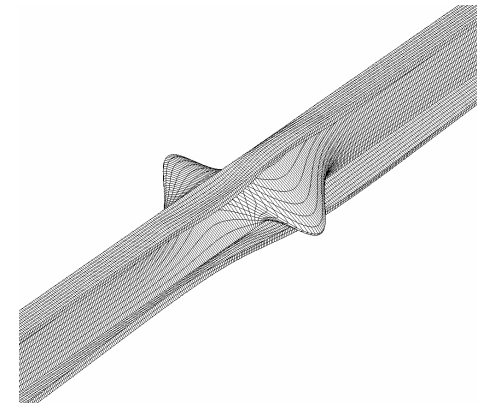

(b) Local flexural deformation of purlin web in FE analysis

Fig. 4. Local flexural deformation of purlin web under opposite forces with offset 


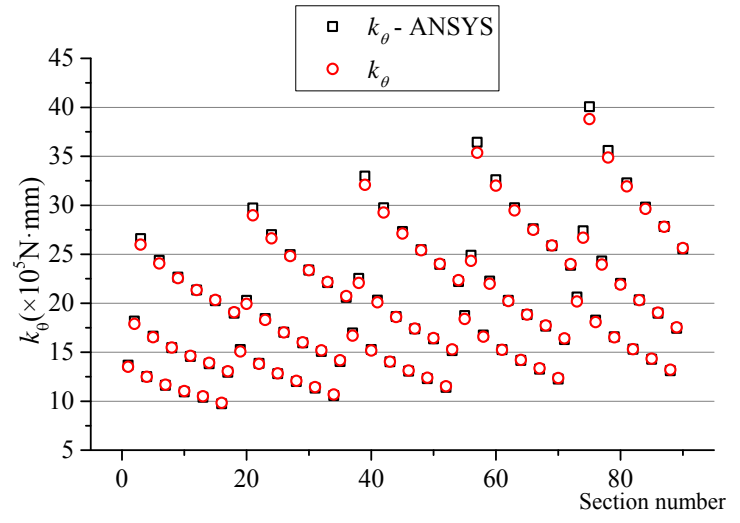

(a) $\xi=0.5$

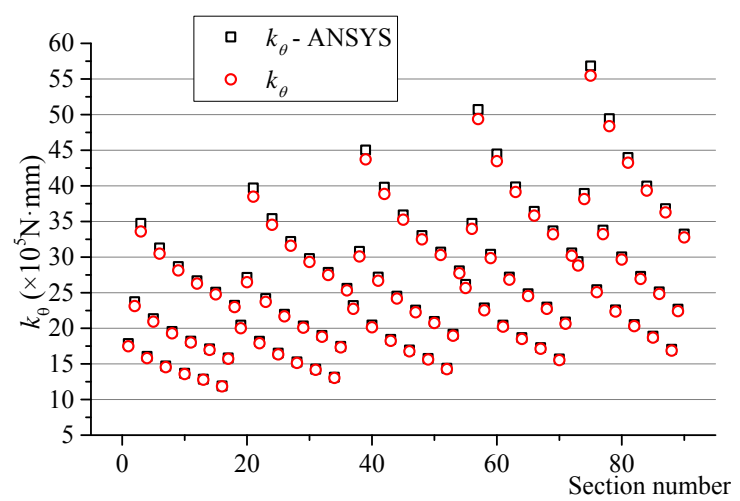

(c) $\xi=0.25$

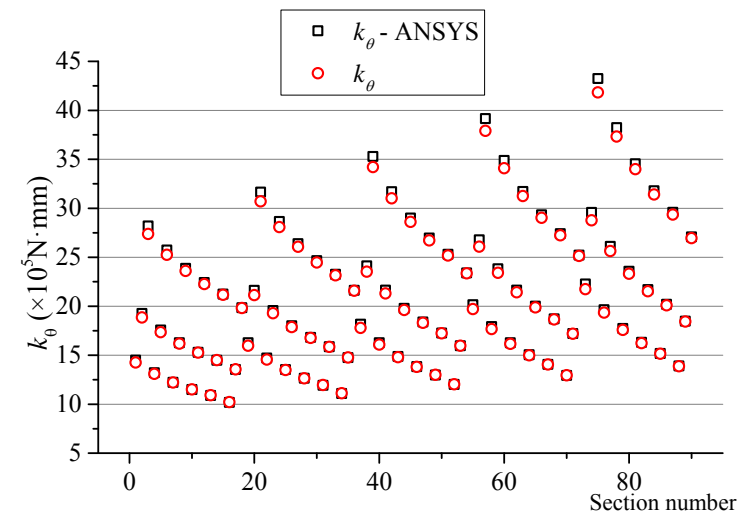

(b) $\xi=0.375$

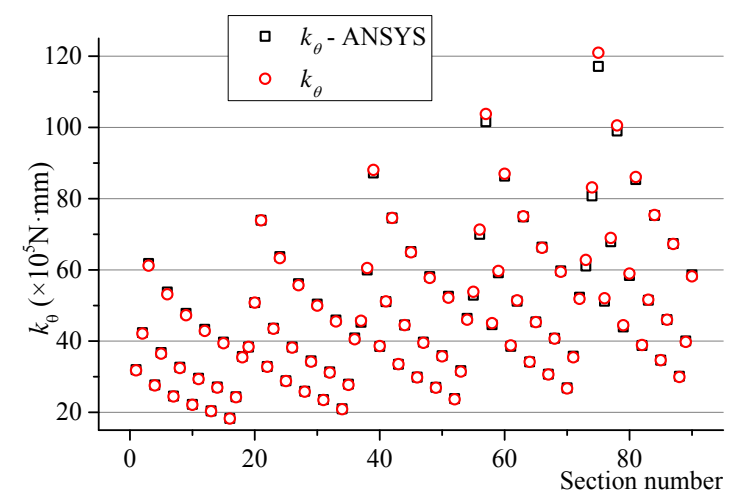

(d) $\xi=0.125$

Fig. 5. The approximations and the FE analytic results of the flexural stiffness

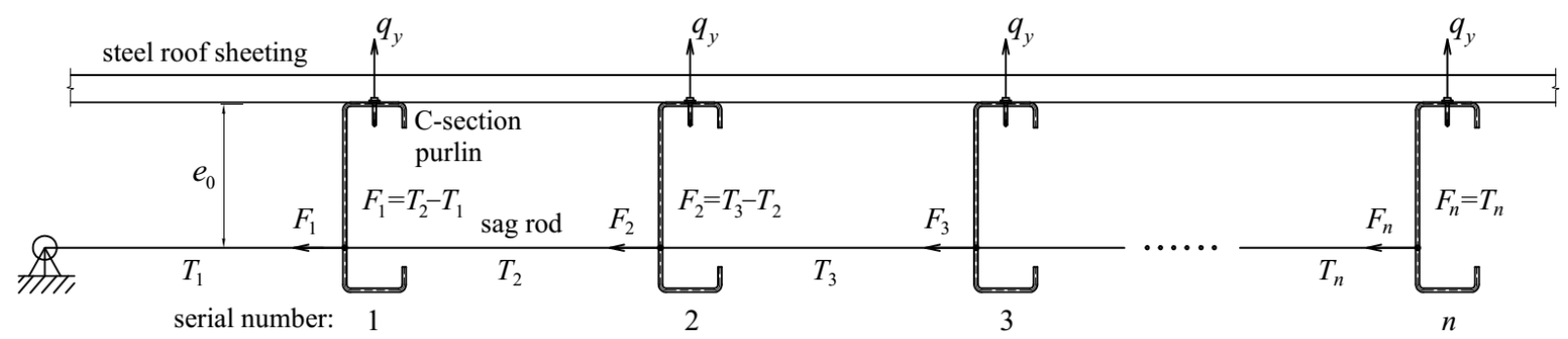

Fig. 6. Line of parallel purlins inter braced by sagrods

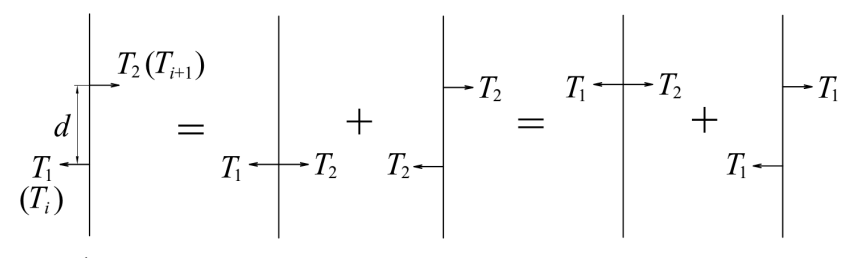

(a)

(b)

(c)

Fig. 7. Equivalent force condition of the first purlin (or purlin with odd serial number) 


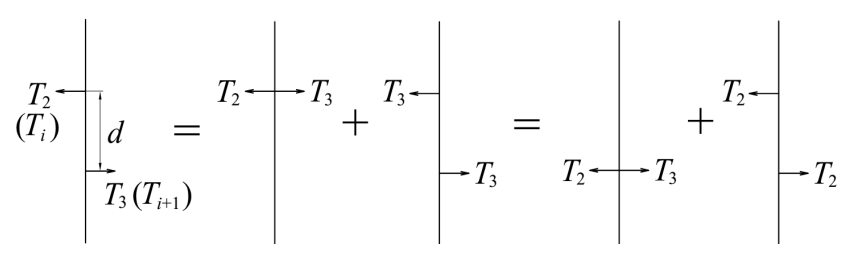

(a)

(c)

Fig. 8. Equivalent force condition of the second purlin（or purlin with even serial number)

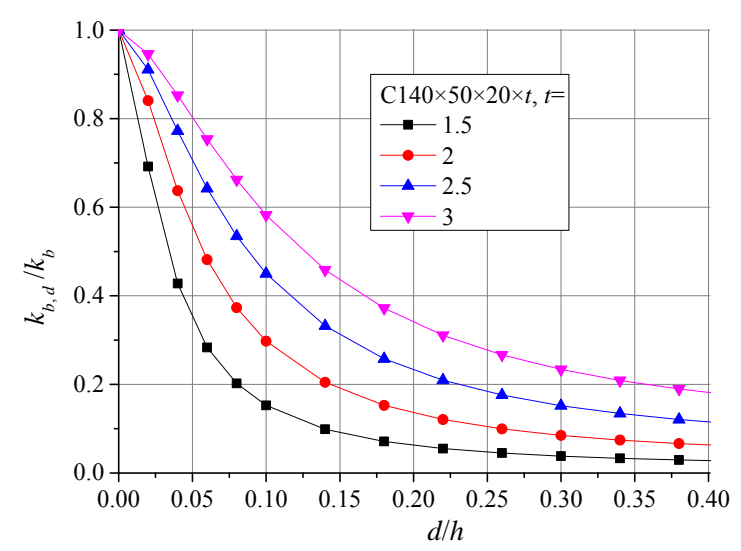

(a) $\mathrm{C} 140 \times 50$

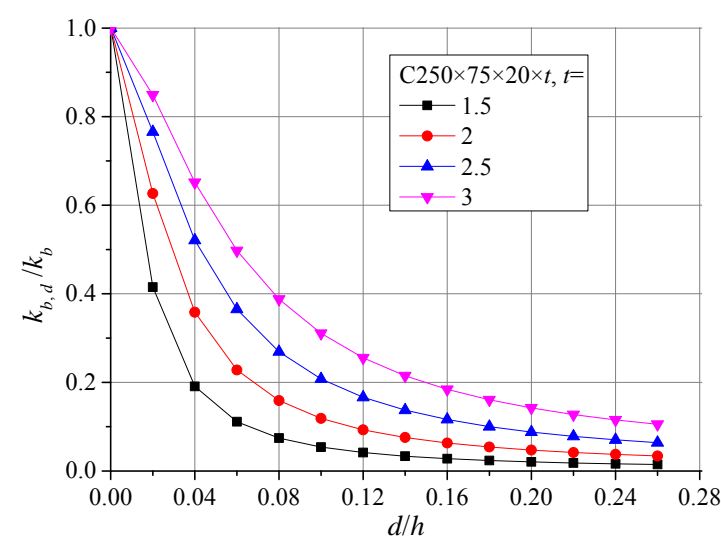

(b) $\mathrm{C} 250 \times 75$

Fig. 9. the effective axial stiffness of the offsetted sagrod

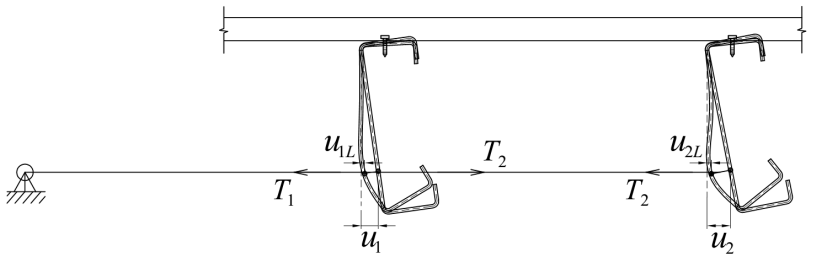

(a) Lateral deformation in each purlin

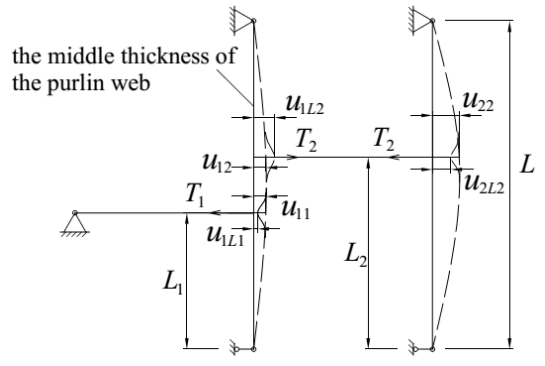

(b) Displacement analysis diagram

Fig. 10. Line of two parallel purlins

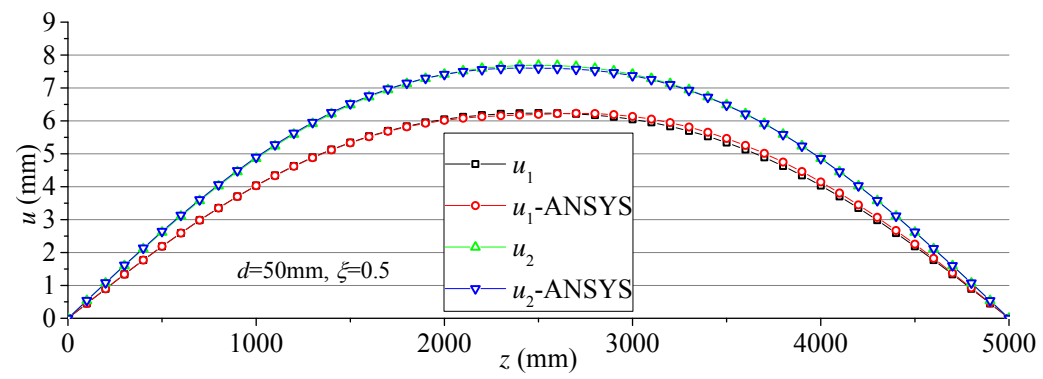

Fig. 11. Theoretical solutions and FE analytic results in line of two parallel purlins ( $\mathrm{C} 250 \times 75 \times 20 \times 2, d=50 \mathrm{~mm}, \xi=0.5)$ 


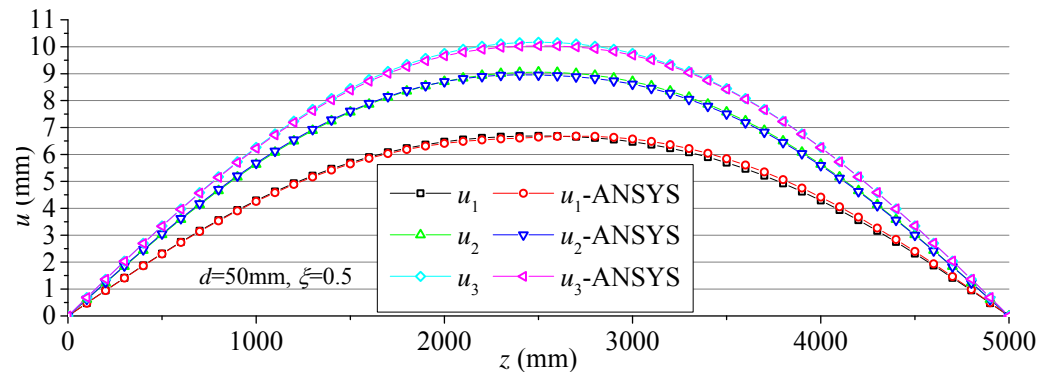

Fig. 12. Theoretical solutions and FE analytic results in line of there parallel purlins $(\mathrm{C} 250 \times 75 \times 20 \times 2, d=50 \mathrm{~mm}, \xi=0.5)$

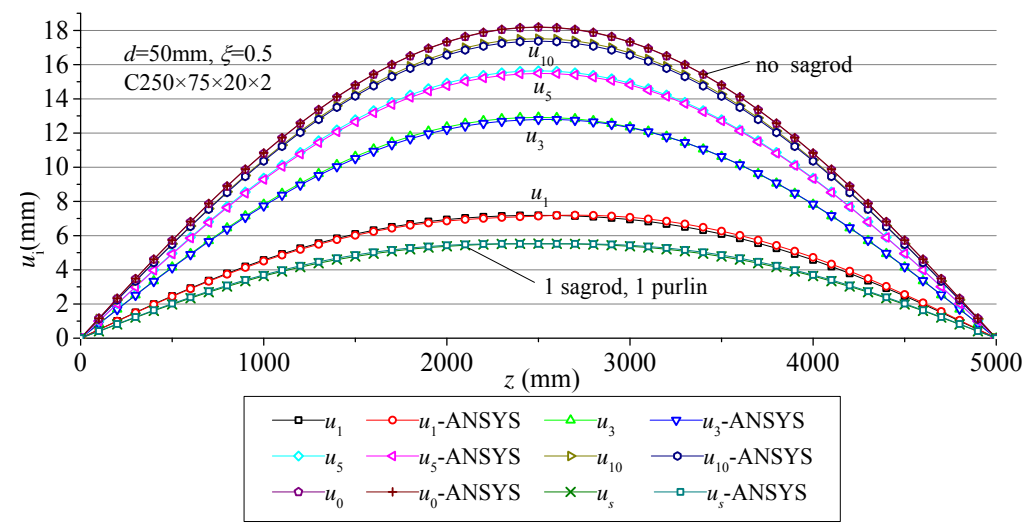

Fig. 13. Theoretical solutions and $\mathrm{FE}$ analytic results in line of 10 parallel purlins $(\mathrm{C} 250 \times 75 \times 20 \times 2, d=50 \mathrm{~mm}, \xi=0.5)$

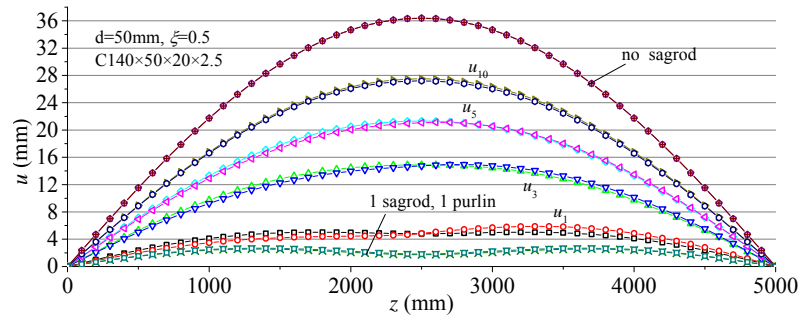

(a) $\mathrm{C} 140 \times 50 \times 20 \times 2.5$

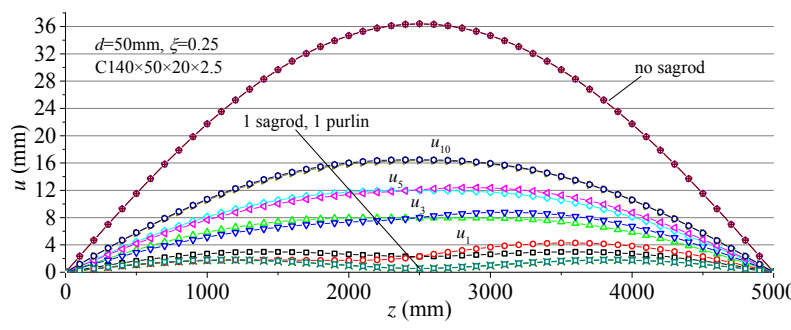

(c) $\mathrm{C} 140 \times 50 \times 20 \times 2.5$

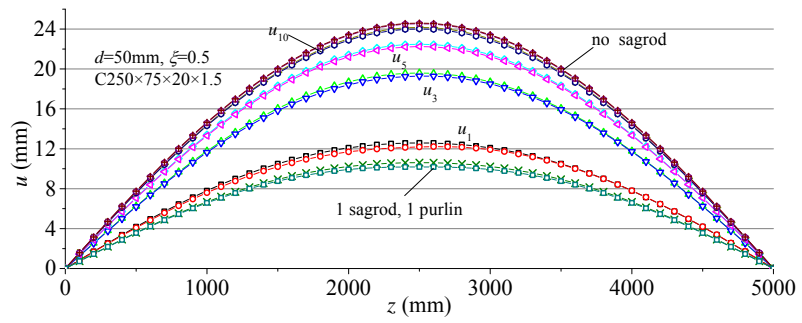

(b) $\mathrm{C} 250 \times 75 \times 20 \times 1.5$

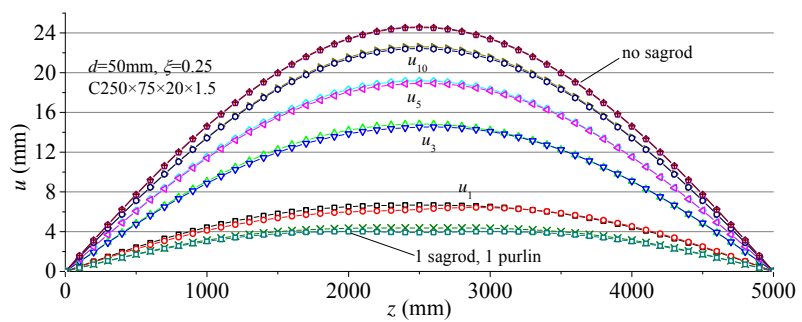

(d) $\mathrm{C} 250 \times 75 \times 20 \times 1.5$ 


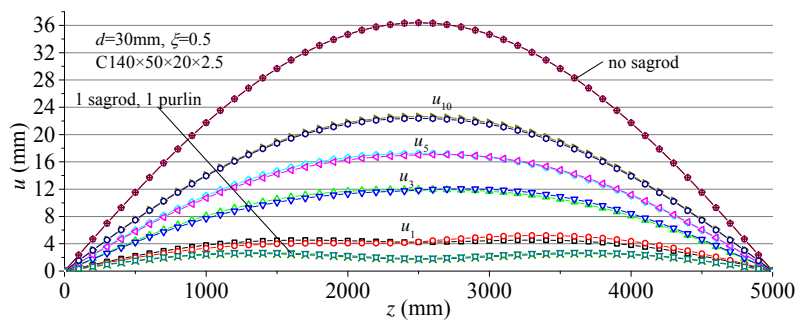

(e) $\mathrm{C} 140 \times 50 \times 20 \times 2.5$

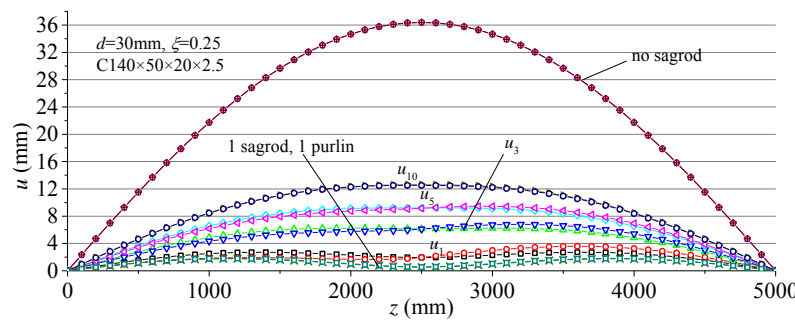

(g) $\mathrm{C} 140 \times 50 \times 20 \times 2.5$

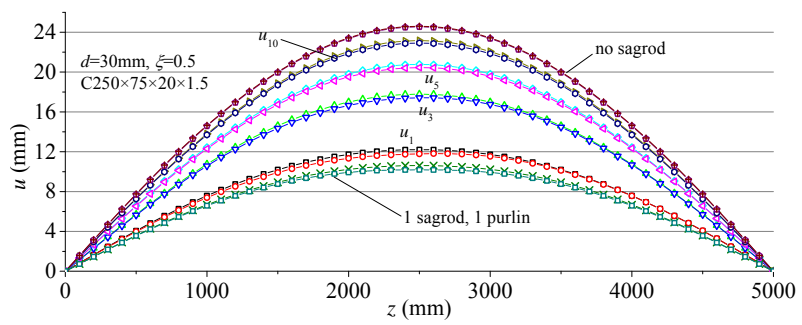

(f) $\mathrm{C} 250 \times 75 \times 20 \times 1.5$

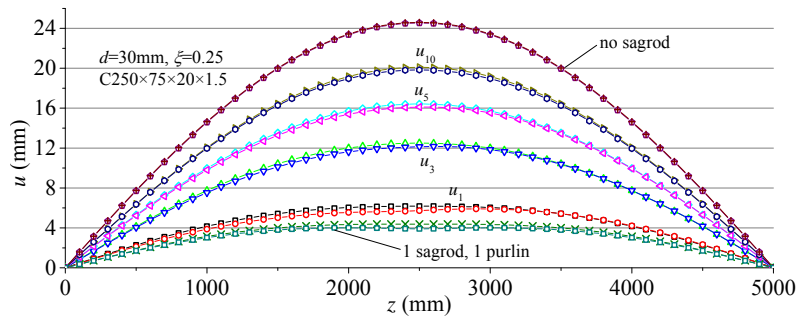

(h) $\mathrm{C} 250 \times 75 \times 20 \times 1.5$

Fig. 14. Theoretical solutions and FE analytic results in line of 10 parallel purlins

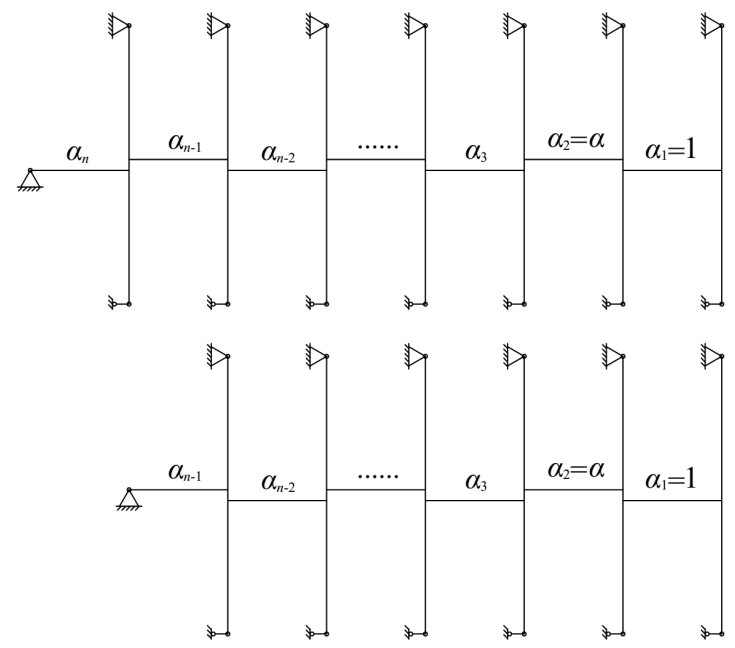

Fig. 15. The ratio of tensions in sagrods in line of parallel purlins with different total amount of purlins

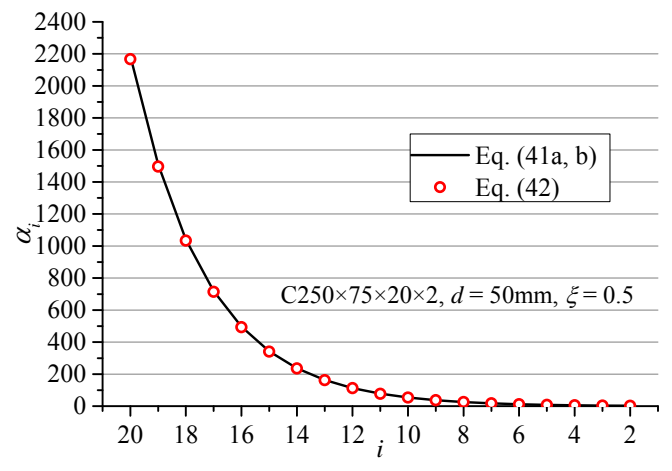

(a)

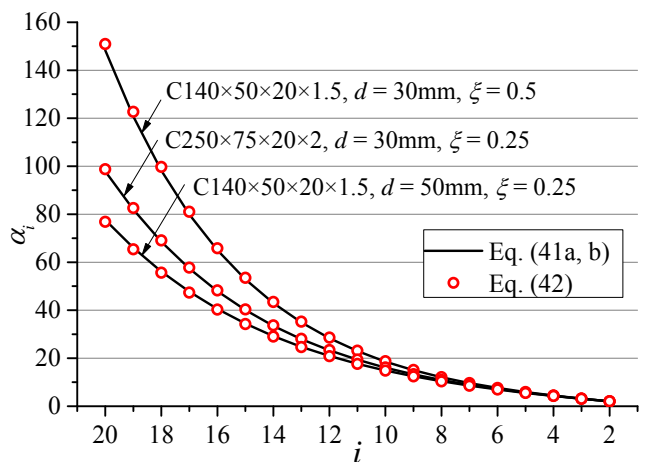

(b)

Fig. 16. The coefficient of tensions in sagrods 


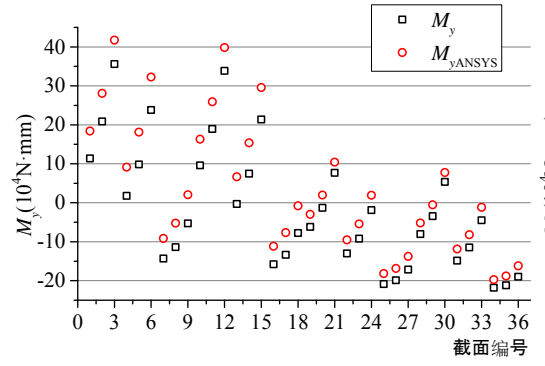

(a) In the $1^{\text {st }}$ purlin

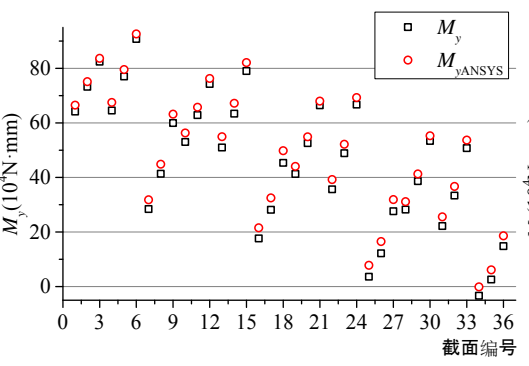

(b) In the $5^{\text {th }}$ purlin

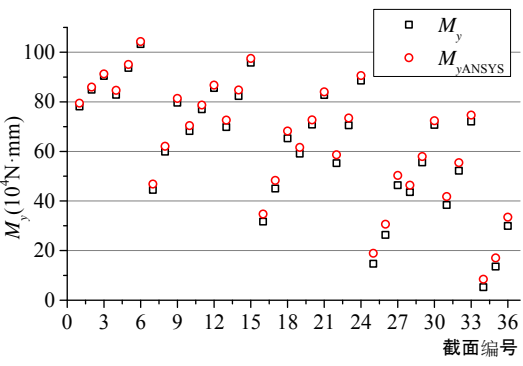

(c) In the $10^{\text {th }}$ purlin

Fig. 17. The theoretical and FE analytic results of $M_{y}$

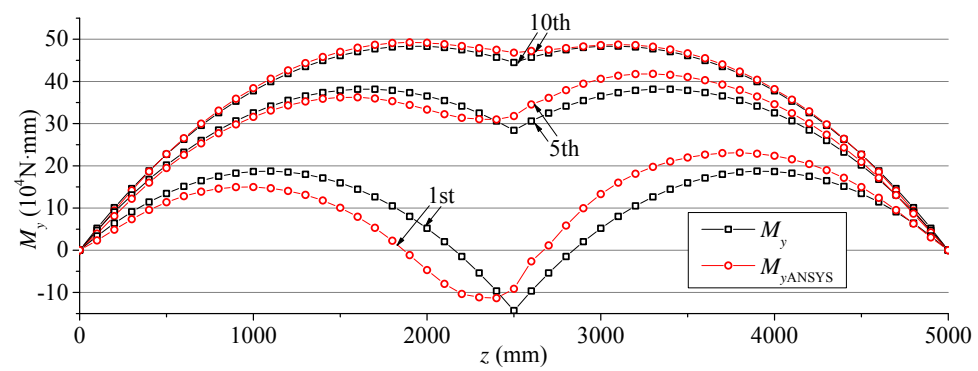

Fig. 18. The distribution of the out-of-plane bending moments of sections along span 
Table. 1. Sections and arrangement ways of sagrods

\begin{tabular}{|c|c|c|c|c|}
\hline Num. & Sections & $d$ & $\xi$ & Remarks \\
\hline 1 & $250 \times 75 \times 20 \times 2.5$ & \multirow{9}{*}{50} & \multirow{9}{*}{0.5} & \multirow{9}{*}{$\begin{array}{l}\text { Conditions Num. } 10-18 \text { are the same } 9 \\
\text { sections, but with } d=30 \text { and } \xi=0.5 ; \\
\text { Conditions Num. } 19-27 \text { are the same } 9 \\
\text { sections, but with } d=50 \text { and } \xi=0.25 \text {; }\end{array}$} \\
\hline 2 & $250 \times 75 \times 20 \times 2.0$ & & & \\
\hline 3 & $250 \times 75 \times 20 \times 1.5$ & & & \\
\hline 4 & $200 \times 70 \times 20 \times 2.5$ & & & \\
\hline 5 & $200 \times 70 \times 20 \times 2.0$ & & & \\
\hline 6 & $200 \times 70 \times 20 \times 1.5$ & & & \\
\hline 7 & $140 \times 50 \times 20 \times 2.5$ & & & \\
\hline 8 & $140 \times 50 \times 20 \times 2.0$ & & & \\
\hline 9 & $140 \times 50 \times 20 \times 1.5$ & & & \\
\hline
\end{tabular}

